Even in the absence of any new resources a plethora of evidence based interventions can be implemented on a large scale fairly rapidly in resource poor countries through family and community oriented services, facilitated by using community participation. In maternal, newborn, and child health these include birth and emergency preparedness; maternal calorie and micronutrient supplementation; insecticide treated bed nets to prevent malaria; clean delivery and simple resuscitation (for home deliveries by trained traditional birth attendants), hygienic care of cord and skin; prevention and management of hypothermia; immediate and exclusive breast feeding; appropriate complementary feeding; extra care of low birth weight infants; healthy home practices and early care seeking in sickness; and management of diarrhoea and pneumonia.

As has been seen in the Nepal and Gadchiroli studies, rural women can be transformed into effective and acceptable agents of change in maternal and child health with training and orientation. ${ }^{4}$ Processes to facilitate community participation can be built on and integrated with other non-health development activities. Community action led by women has the potential to change societies.

One of the biggest challenges in health, namely neonatal and maternal mortality, is the bane of the less developed countries. Of the 3.9 million neonatal deaths, $98 \%$ occur in low income countries. ${ }^{11}$ Likewise, almost all $(99.5 \%)$ of the 529000 maternal deaths occur in the developing regions of the world. ${ }^{12}$ Although the medical cause of an illness is the same everywhere, contribution of indirect causes and risk factors is different in poor societies compared with affluent ones. Access to effective health care determines the survival of a sick child or mother once a serious illness sets in; but the health systems in the resource restricted countries, or regions within countries, have little resemblance to those in resource- rich settings. Inevitably, even though interventions (such as drugs, vaccines, or healthy behaviours) are universal, effective delivery strategies to take them to the needy in the prevailing socioeconomic and cultural and health system scenarios are likely to be quite different in the developing countries. We need more investment in relevant research in developing countries to find local solutions to health problems, and we need to create new opportunities for sharing of experiences between developing countries in the delivery of health care.

Vinod Paul senior policy adviser, Saving Newborn Lives Saving Newborn Lives/Save the Children, and All India Institute of Medical Sciences, D-II-29 Ansari Nagar, AIIMS Campus, New Delhi 110029, India

(vinodpaul@neonatalhealth.com)

Competing interests: None declared.

1 Haines A, Cassels A. Can the millennium development goals be attained? BMJ 2004;329:394-7.

2 World Health Organization. Health systems: improving performance. Geneva: WHO, 2000.

3 Howard-Grabman L, Seone G, Davenport C. The Warmi project: a participatory approach to improve maternal and neonatal health: an implementer's manual. Westport: John Snow International Mothercare Project, Save the manual. Westport:
Children, 2002 .

4 Manandhar DS, Osrin D, Shreshtha BP, Mesko N, Morrison J, Tumbahangphe KM, et al. Effect of a participatory intervention with women's groups on birth outcomes in Nepal: cluster-randomized controlled trial. Lancet 2004;364:970-9.

5 Fullerton JT, Killian R, Gass PM. The community partnerships for safe motherhood. The PRIME II project: Final evaluation report. Chapel Hill: PRIME II Project, 2003.

6 World Bank. The millennium development goals for health. Rising to the challenges. Washington DC: World Bank, 2004

7 Pratinidhi A, Shah U, Shrotri A, Bodhani N. Risk-approach strategy in Pratinidhi A, Shah U, Shrotri A, Bodhan
neonatal care. Bull WHO 1986;64:291-7.

8 Bang AT, Bang RA, Baitule S, Reddy MH, Deshmukh M, Effect of home Bang AT, Bang RA, Baitule S, Reddy MH, Deshmukh M, Effect of home
based neonatal care and management of sepsis of neonatal mortality: field trial as rural India. Lancet 1999;354:1955-61.

9 Datta N, Kumar V, Kumar L, Singh S. Application of case management to the control of acute respiratory infections in low-birth-weight infants; a feasibility study. Bull WHO 1987;65:77-82.

10 World Bank. Making services work for the poor. World development report. Washington DC: World Bank, 2004.

11 Saving Newborn Lives, Save the Children. State of world's newborns. Washington DC: Saving Newborn Lives, Save the Children, 2001.

12 World Health Organization, UNICEF, United Nations Population Fund. Maternal mortality in 2000. Geneva: WHO, 2004.

\title{
Highly active antiretroviral therapy
}

\author{
We need to scale up its use and reach with existing facilities in poor countries
}

$\mathrm{T}$ The barriers to providing highly active antiretroviral therapy (HAART) in poor countries have until recently seemed insurmountable. The cited problems have ranged from weak health systems and poor infrastructure to inadequate numbers of health professionals. In reality, the main barrier has been the very high cost of antiretroviral drugs. Current increase in access to HAART has resulted from cuts in the price of antiretroviral drugs and increased funding by international bodies, notably the Global AIDS Fund, the World Bank, and the President Bush Emergency Program for AIDS Relief.

Africa's grim AIDS data include 25 million people living with HIV and 2.2 million dead in 2003 alone. ${ }^{1}$ The challenge now is to move quickly from small town or community specific projects to provide nationwide high quality, equitable, and sustainable programmes. Valuable lessons have been learned from pilot programmes in poor countries, including the Malawi experience described in this issue, but individually these do not provide a blueprint for universally applicable scale-up models (p 1163). ${ }^{2}$ However, if the cumulative knowledge from these programmes is applied with tactical adjustment tailored to the local conditions it should be sufficient for programmes to proceed, without the need for new pilot studies, which would be unethical if they deny or delay the provision of life saving treatment to patients.

The dreaded risk associated with scaling up HAART is the development of widespread drug resistance secondary to drug misuse, ${ }^{3}$ which in the long term may render the cheap first line antiretroviral
Education and debate p 1163

BMJ 2004;329:1118-9 
drugs ineffective. Although initial data indicate good adherence $^{4}$ and treatment outcomes in Africa, it is critical to enforce and maintain strong adherence strategies, as it is the key to success in controlling the carnage caused by HIV/AIDS.

\section{Tuberculosis control practices}

Recommendations to accelerate quality HAART programmes include the application of best tuberculosis control practices, especially direct observation of treatment strategy. Additionally, the dangerous HIVtuberculosis coinfection, described as "a collaboration to kill," supports calls for collaborative interventions. Since up to $75 \%$ of patients with tuberculosis are coinfected with HIV, joint interventions, including voluntary counselling and testing, and tuberculosis diagnostics are vital for effective management of the two diseases. ${ }^{5}$

Unlike tuberculosis, however, HIV is a lifetime illness with different modes of transmission and a much higher stigma. Furthermore, because such huge numbers are infected, strategies used against tuberculosis are not always appropriate or sufficient for HIV and may need tactical modification. Paul Farmer's team in rural Haiti has successfully shown that people who accompany peasants can be partners for effective antiretroviral therapy. The accompanying persons are recruited from within the community, to supervise and provide HAART directly observed therapy, short course. ${ }^{6}$ Other variants of DOTS have used patients' confidants - mainly friends, relatives, or neighbours - to fill the staffing gap in counselling and follow up of patients.

Brazil's successful universal AIDS treatment programme initially started by using mainly clinical monitoring based on recommendations from the World Health Organization and the US Centers for Disease Control and Prevention, and simple laboratory tests, then progressively built capacity over time. ${ }^{7}$ This experience shows that HAART scale up in other poor and medium income countries can proceed expeditiously, using whatever facilities are available, while systematically building capacity, including training healthcare providers, establishing laboratories, drugs supply logistics, and monitoring and evaluation tools. Mobile clinics may be used successfully to take services to hard to reach populations.

\section{Stepwise strategy}

We need to plan and draw together a stepwise strategy that incorporates other AIDS interventions, including prevention of transmission from mother to child, voluntary counselling, and testing as well as other preventive strategies, such as distribution of condoms, into a comprehensive programme that will ultimately integrate into an improved robust national healthcare system.

In developing countries, most public healthcare facilities are crammed with AIDS patients over and above other rampant endemic diseases, including opportunistic infections and malaria. Healthcare providers are overworked and poorly paid; some are themselves sick or have seen colleagues die. ${ }^{8}$ They need to be supported and motivated to carry out their tasks by incentives such as improved remuneration, better working conditions, and access to treatment. ${ }^{9}$ To expect to set up a successful AIDS treatment programme is unrealistic if other vital health needs are ignored. New antiretroviral therapy facilities, including laboratories, need to benefit other health services, which serve patients and staff with other needs.

\section{Staff shortages}

The shortage of healthcare providers may be partly compensated for by training and involving community based organisations such as People Living With HIV/ AIDS, which can provide the human resources to help with ongoing support and follow up of patients. As in all emergencies, imaginative problem solving should be encouraged. For example, the Joint Clinical Research Centre's AIDS clinic in Uganda once ran short of space because of a sudden surge of patients as a result of the lowering of the price of HAART. Pitching tents alleviated the problem. The practice has been applied successfully to other deficient facilities while funds are being sought for more permanent arrangements.

In the absence of a fully replicable universal scale up model to deliver HAART, a hybrid approach that takes into account the diversity within and between countries is the most practical way forward. And for them to be sustained programmes must be planned, led, implemented, managed, and owned by host countries or carried with their full participation.

Continued advocacy for affordable drugs and monitoring laboratory tests and better patent laws to allow access to lower cost quality generics are needed along with focused international support. But in the long term, the only the way for poor countries to ensure that they become self sustainable in dealing with HIV/AIDS and other future disasters is for them to establish good governance and policies that promote social economic development to lift them out of the poverty trap.

\section{Peter Mugyenyi director}

Joint Clinical Research Centre, 1 Ring Road, Mengo, PO Box 10005, Kampala, Uganda

(pmugyenyi@yahoo.co.uk)

Competing interests: None declared.

1 World HIV and AIDS Statistics Including Deaths: UNAIDS 2004 report on global AIDS epidemic. www.avert.org/worldstats.htm (accessed 22 Oct 04). Harries AD, Libamba E, Schouten EJ, Mwansambo A, Salaniponi FM, Mpazanje R. Expanding antiretroviral therapy in Malawi: drawing on the country's experience with tuberculosis. BMJ 2004;329:1163-6.

3 Adje C, Cheingsong R, Roels TH, Maurice C, Djomand G, Verbiest W, et al. High prevalence of genotypic and phenotypic hiv-1 drug-resistant strains among patients receiving antiretroviral treatment in Abidjan, Cote d'Ivoire. J Acquir Immune Defic Syndr 2001;26:501-6.

4 Oyugi JH, Byakika-Tusiime J, Charlebois ED, Kityo C, Mugerwa R, Mugyenyi $\mathrm{P}$, et al. Multiple validated measures of adherence indicate high levels of adherence to generic hiv antiretroviral therapy in a levels of adherence to generic hiv antiretroviral therapy in
resource-limited setting. J Acquir Immune Defic Syndr 2004;36:1100-02.

5 Joint UNAIDS WHO Press Release. Combining TB treatment with HIV testing and treatment. www.unaids.org/en/media/press+releases.asp (accessed 7 Oct 2004)

6 Farmer P, Leandre F, Mukherjee JS, Claude M, Nevil P, Smith-Fawzi MC et al. Community based approaches to HIV treatment in resource-poor settings. Lancet 2001:358:404-9.

7 Schechter M. Expert commentary: Scaling up antiretroviral therapy for developing countries-we can walk and chew gum at the same time. 2nd International Society Conference on HIV Pathogenesis and Treatment. 13-16 July 2003, Paris, France. www.impactaids.org.uk/med6.htm (accessed 28 Oct 2004).

8 Mpundu M. The burden of HIV/AIDS on the Zambian health system. AIDS Anal Afr 2000;10:6.

9 Uebel K, Friedland G, Pawinski R, Holst H. HAART for hospital health care workers-an innovative programme. S Afr Med J 2004;94:423-7. 